\title{
CORRESPONDENCE
}

The end of excellence?

J W Todd, FRCP...............1130

DNCB, chemical laboratory workers, and chloramphenicol

R J Pye, MRCP, and J L Burton, MD......1130

Reactions to current influenza vaccine

$\mathrm{T} \mathbb{W}$ Hoskins, MB ................ 1131

Side effects of prazocin

M J Bendall, MRCP; C Rosendorff, MRCP. . 1131

Chemotherapy in breast cancer

J Wilkinson ....................1132

Compulsory seat belts

M J W Barker, MA...............1132

Neonatal electrocardiogram

H Watson, FRCP; D P Southall, MRCP . . . . . 1132 "Press that bruise"

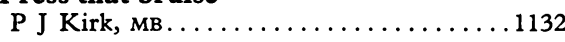

Hyposensitisation with house dust mite

vaccine in bronchial asthma

J Gaddie, $\mathrm{MD}$, and others...........1132

Risk of venepuncture

D Kohn, MD, and others............1133

Thyrotoxic vomiting

P Skrabanek, LAH; B I Chazan, FRCP......1133

Coronary artery disease and coalworkers'

pneumoconiosis

G S Andrews, frCPath...........1133
Professional standards

M C T Morrison, fRCs . . . . . . . . . . . . 1133

Traumatic rupture of ear drum

D McCracken, FRCP...............1133

Direct translation

H-D Pache, MD . . . . . . . . . . . . . 1134

Oculo-mucocutaneous reactions to

$\beta$-adrenoceptor antagonists

J C Petrie, MrCP.................1134

Misuse of tubular elasticated bandages

J B Bourke, FRCS. . . . . . . . . . . 1134

In vitro lymphocyte reactivity during pregnancy

Y W Loke, MD, and others..........1134

Intravenous and aerosol salbutamol

S P Deacon, MB . . . . . . . . . . . . . . . . . 1134

Can hepatitis $B$ be transmitted sexually?

N R Grist, FRCPED . . . . . . . . . . . . . 1134

Propranolol absorption in Crohn's

disease and coeliac disease

B T Cooper, MRCP, and others........1135

Sedatives and driving

J M Plumb, MRCP..................1135

Detection of paraquat in urine

B Widdop, PHD..................1135

White coat

D J Vicary, MrCP.................1135
Not cricket

J P Sparks, MD................. 1135

The hospitals we need

P R J Vickers, FRCS. .

Closure of cottage hospitals

D M Baker, MD .................1136

Unpopular specialties

F M Lanigan-O'Keeffe, MD . . . . . . . . . . . 1136

JHDA and HJSC

D F H Guèret Wardle, MRCP, and others. .1136

Loss of earnings through committee

attendances

G S Duncan, MRCGP.............. 1137

Health Service charges

V Cooper, MB..................1137

Hospital practitioner grade

W D Waller, MB, Do................1137

National Insurance deductions

J W Jackson, FRCS. . . . . . . . . . . . . . . 1137

Pay differentials

A A McInnes, MrCGP............. 1137

BMA and HCSA

Margaret C Watkinson, MB...........1137

Suspended consultant

A J G Davis, MB .................1137

Royal Medical Benevolent Fund

Christmas appeal

Sir Geoffrey Bateman, FRCS. . . . . . . . . 1137
Correspondents are urged to write briefly so that readers may be offered as wide a selection of letters as possible. So many are being received that the omission of some is inevitable. Letters should be signed personally by all their authors.

\section{The end of excellence?}

SIR,-Your leading article (2 October, p 779) begins: "Throughout the world there are a few hospital complexes where the quality of care given to patients, the teaching, and the academic research reach the highest possible standards." You also refer to "excellence," which requires a "concentration of medical talent and technological hardware", and comment that the centres of excellence improve standards and advance medicine far beyond their boundaries.

What are the criteria which determine that an institution is excellent? And how can we judge quality of care and standards of management? A few years ago in the most famous hospitals patients with small cancers of the breast were having radical mastectomies, patients with ankylosing spondylitis were immobilised for months on plaster beds, and patients with low backache were having their round ligaments shortened so as to antevert their retroverted uteruses. Patients with uncomplicated duodenal ulcer were kept in bed for weeks being fed initially on citrated milk every two hours and later with the gradual addition of gruel, minced steamed fish, lightly poached eggs, rusks (to be well chewed), etc, until they were finally advised for ever after to avoid roast and fried dishes, salads, spices and seasoning, and most of the other features which make food attractive. Patients with cardiac infarcts were kept at absolute rest for a week or two and strictly in bed for six weeks and thereafter advised to live semi-invalid lives.
Patients with diverticulitis were given residuefree diets, and patients who were poisoned were given analeptic drugs and the poison was flushed out of them by forced diuresis. Were the hospitals where all this took place excellent? And were these patients being given care of the highest possible standard?

A commonly seen patient in the outpatient department is the middle-aged woman with multiple symptoms such as unpleasant head sensations, persistent low backache, being always tired and run down, widespread "rheumatism," and "indigestion." If she is seen by a physician who believes it is not his business to delve into his patients' emotions, concentrates his attention on her bodily symptoms, and admits her for a vast series of investigations is she being treated by the highest standards? Indeed, a feature of modern medicine as practised in the most famous hospitals is the ever-increasing number of investigations, many of which are done as

The great majority of patients are not helped by being treated in an institution filled with the latest technological hardware and staffed with a galaxy of talent. They merely need a doctor with nous and sympathetic understanding. And the most excellent place for most of them is their own homes. Even if there are grounds for their being in hospital the most important of these grounds, if they have a medical illness, is often social; they may be living alone or old, with the main need routine. Is this an example of excellence? of nursing care. Those with most surgical conditions do just as well in a basic hospital; their prime need is a competent surgeon who performs the right operation at the right time.

May I finally suggest that we should all be wary of using such words as "excellence" and "standards"? We constantly hear assertions about standards-how they are rising or, more often, falling-according to the particular axe that the writer is grinding. Such assertions are mostly quite meaningless.

JOHN W TODD

Farnham, Surrey

DNCB, chemical laboratory workers, and chloramphenicol

SIR,-2, 4-Dinitrochlorobenzene (DNCB) is a potent sensitiser which is widely used in medicine to test the integrity of the immune response in experimental animals or human patients. Most organic chemists appear to be unaware of its sensitising properties, and DNCB is a standard laboratory preparation which is used for the routine preparation of derivatives.

We recently treated two laboratory technicians who had both taken a practical organic chemistry examination which involved the preparation of DNCB. The first patient was a 23-year-old man who had not allowed the DNCB to come into direct contact with his skin, but he had spilt some of the prepared DNCB solution on to his examination paper, which he had then put into the back pocket of his trousers to discuss with his friends after the examination. Some $24 \mathrm{~h}$ later he developed a widespread urticated eczematous eruption which was maximal over the right buttock and which also involved the chest, abdomen, arms, and hands. The rash subsided rapidly with prednisone $50 \mathrm{mg}$ daily 